\title{
Structure of Ulvan Isolated from the Edible Green Seaweed, Ulva pertusa
}

\author{
Masakuni Tako',2*, Makie Tamanaha1, Yoshiyuki Tamashiro', Shuntoku Uechi' ${ }^{1}$ \\ ${ }^{1}$ Department of Subtropical Bioscience and Biotechnology, University of the Ryukyus, Nishihara, Okinawa, Japan \\ ${ }^{2}$ Health and Longevity Science Research Laboratory, Integrated Innovation Research Center, University of the \\ Ryukyus, Nishihara, Okinawa, Japan \\ Email: tako@agr.u-ryukyu.ac.jp
}

Received 25 August 2015; accepted 27 October 2015; published 30 October 2015

Copyright (C) 2015 by authors and Scientific Research Publishing Inc.

This work is licensed under the Creative Commons Attribution International License (CC BY).

http://creativecommons.org/licenses/by/4.0/

(c) (i) Open Access

\begin{abstract}
Ulvan, rhamnan sulfate, was extracted from the edible green seaweed, Ana-aosa (Ulva pertusa), which is grown on the coast of the Okinawa Islands. The yield of ulvan was $8.5 \%(\mathrm{~W} / \mathrm{W})$, and the total carbohydrates, uronic acid and sulfuric acid and ash contents were $67.3 \%, 23.8 \%, 19.7 \%$ and $\mathbf{2 2 . 6 \%}$, respectively. L-Rhamnose, D-xylose and D-glucose residues were identified by liquid chromatography, and their molar ratio was 4.0:0.1:0.3. D-Glucuronic and L-idulonic acid residues were also identified in molar ratio of 1.0:0.2. The NMR $\left({ }^{13} \mathrm{C}\right.$ and $\left.{ }^{1} \mathrm{H}\right)$ and methylation analysis revealed terminal $\beta$-D-glucruonic acid, terminal $\alpha$-L-idulonic acid, 1,3-linked $\alpha$-L-rhamnose, 1,4-linked $\alpha$-L-rhamnose, 1,2,4-linked $\alpha$-L-rhamnose, 1,3,4-linked $\alpha$-L-rhamnose, 1,2,3,4-linked $\alpha$-L-rhamnose and 1,3,4-linked $\beta$-D-xylose. The sulfate groups were attached at the $\mathrm{C}-2$ and $\mathrm{C}-3$ positions of the 1,4-linked $\alpha$-L-rhamnose as well as C-3 of the 1,4-linked $\beta$-D-xylose residues. The chemical structure of the ulvan from Ulva pertusa was determined.
\end{abstract}

\section{Keywords}

Ulva pertusa, Ulvan, NMR Analysis, Methylation Analysis, Chemical Structure

\section{Introduction}

In the course of the chemical, physicochemical and biological studies of polysaccharides, we investigated structure-function relationship of $\kappa$-carrageenan [1] [2], $l$-carrageenan [3], agarose [4], gellan gums [5] [6], rhamsan gums [7] [8], amyloses [9] [10], amylopectins [11]-[15], and starches [16]-[20]. The results and discussions led

\footnotetext{
${ }^{*}$ Corresponding author.
}

How to cite this paper: Tako, M., Tamanaha, M., Tamashiro, Y. and Uechi, S. (2015) Structure of Ulvan Isolated from the Edible Green Seaweed, Ulva pertusa. Advances in Bioscience and Biotechnology, 6, 645-655. 
us to realize their gelation, gelatinization, or retrogradation mechanisms in principle [21]-[23].

We isolated many industrially useful polysaccharides, such as agar [24], methylated agar [25], $\kappa$-carrageenan [26], $\boldsymbol{l}$-carrageenan [27], fucoidans [28]-[30], alginates [31] [32], galactomannans [33] [34], pectins [35]-[37], and rhamnan sulfate [38] from the subtropical biomasses grown in Okinawa Islands, Japan.

In the previous studies, we identified fucoidans from commercially cultured Okinawamozuku (Cladosiphon okamuranus) [28] and Itomozuku (Nemacystus decipiens) [29]. Specifically, a novel fucoidan which was substituted with an acetyl group from the commercially cultured brown seaweed, Cladosiphon okamuranus [28] [32] was identified and patented [39]. The acetyl fucoidan exhibits some biological activities, such as antitumor [40] and immune-enhancing abilities [41]. An over-sulfated acetyl fucoidan, the sulfate content of which was $32.8 \%$, showed a significant antitumor activity in vitro [40]. The results suggested that the over-sulfated acetyl fucoidan was applicable as an anticancer drug. Recently, the chemical structure of the acetyl fucoidan was determined [41]. The acetyl fucoidan consists of 1,3-linked $\alpha$-L-fucopyranosyl residues and a branched $\beta$-D-glucuronopyranosyl residue at C-2 on the main-chain. The sulfate and acetyl groups branched at C-4 on the main chain. We also isolated a rhamnan sulfate from commercially cultured Hitoegusa (Monostroma nitidum: green seaweed) in Okinawa Prefecture, Japan and determined its chemical structure [38]. The rhamnan sulfate consists of 1,3-linked $\alpha$-L-rhamnopyranosyl residues that branch at C-2 with trisaccharide side chains, D-GlcA $(1 \rightarrow 2)$ $\alpha$-L-Rha- $(1 \rightarrow 2)-\alpha$-L-Rha- $(1 \rightarrow$. The acetyl fucoidan is now used as a supplement in health food, food and cosmetic industries in the world.

Ulva pertusa, an edible green seaweed is widespread in the natural environment of Japan, South Korea and China. The seaweed contains water-soluble rhamnan sulfate, which is referred to as ulvan [42]. The chemical structure of part of the ulvan from Ulva pertusa has been reported [43] [44]. This paper describes the fine chemical structure of the ulvan from Ulva pertusa.

\section{Materials and Methods}

\subsection{Materials}

Ulva fertusa was collected from the coast of Tomishiro City, Okinawa, Japan on April, 2007. The algae were washed with tap water and air dried at $40^{\circ} \mathrm{C}$ for $48 \mathrm{~h}$ before being ground into powder.

The sample ( $20 \mathrm{~g}$ ) was suspended in distilled water adjusted to a $\mathrm{pH}$ of 3.0 with $0.05 \mathrm{M}$ hydrochloric acid and stirred at $60^{\circ} \mathrm{C}$ for $3 \mathrm{~h}$ to extract the polysaccharide. The extract was neutralized with a $0.01 \mathrm{M} \mathrm{NaOH}$ solution, and then centrifuged at 23,000 $\mathrm{g}$ at $4^{\circ} \mathrm{C}$ for $20 \mathrm{~min}$. The supernatant was filtered through Celite 545 (Nakarai, Japan). The filtrate was precipitated by adding 2 volumes of ethanol, and the resulting solid was dried in vacuo.

The crude polysaccharide was dissolved in distilled water and the solution was passed through Celite 545. The filtrate was deionized by passing through a cation exchange column composed of Amberlite $120 \mathrm{~A} \mathrm{H}^{+}(\mathrm{Or}-$ gano, Japan) and neutralized. The solution was subsequently lyophilized.

\subsection{Chemical Procedures}

The total carbohydrate and uronic acid content were determined with the phenol-sulfuric acid [45] and carbazolsulfuric acid [46] methods using L-rhamnose and D-glucuronic acid as standards, respectively. The purified polysaccharide $(70 \mathrm{mg})$ was dissolved in distilled water $(20 \mathrm{~mL})$ and sulfuric acid was added to reach a final concentration of $1.0 \mathrm{M}$. The mixture was subsequently heated to $100^{\circ} \mathrm{C}$ for $3 \mathrm{~h}$. The hydrolysate was neutralized with $\mathrm{BaCO}_{3}$.

\subsection{High-Performance Anion Exchange Chromatography Coupled with a Pulse Amperometric Detector (HPAEC-PAD)}

The monosaccharides in the hydrolysate of the polysaccharide were identified using a HPAEC (DX-500, Dionex Co., CA, USA), fitted with a Carbopack PA1 column and a pulsed amperometric detector. The column was eluted at flow rate of $1 \mathrm{~mL} / \mathrm{min}$ at $35^{\circ} \mathrm{C}$ with $10 \mathrm{mM} \mathrm{NaOH}$.

\subsection{Determination of the Sulfate and Uronic Acid Contents}

Purified polysaccharide (10 mg) was dissolved in distilled water and hydrochloric acid was added to reach a 
final concentration of $1.0 \mathrm{M}$. The mixture was heated at $100^{\circ} \mathrm{C}$ for $3 \mathrm{~h}$. The hydrolysate was allied to HPAEC (DX-500, Dionex Co., CA, USA), on a column (A-SC4) equilibrated with $1.7 \mathrm{mM} \mathrm{NAHCO}+1.8 \mathrm{mM} \mathrm{NaCO}_{3}$. The chromatography was carried out at $35^{\circ} \mathrm{C}$ using a flow rate of $1.0 \mathrm{~cm} / \mathrm{min}$.

\subsection{Desulfation of the Polysaccharide}

The aqueous solution of the purified polysaccharide was passed through a cation exchange chromatography column (Dowex $50 \mathrm{~W}$, Dow Chemical Co.) and was neutralized with pyridine. Then it was dialyzed overnight. The dried sample was dissolved in a $90 \%$ DMSO $+10 \%$ methanol solution and heated at $80^{\circ} \mathrm{C}$ for $4 \mathrm{~h}$ under a $\mathrm{N}_{2}$ atmosphere [38] [41]. Then the sample was dialyzed, and freeze-dried.

\subsection{Infrared Spectrum and Specific Rotation of the Polysaccharide}

The infrared spectrum of the polysaccharide was recorded in $\mathrm{KBr}$ discs using a spectrophotometer (FTS-3000; Bio-Rad Laboratories Inc., CA, U.S.A.) in transmittance mode from 4000 to $400 \mathrm{~cm}^{-1}$.

The specific rotation was measured at $589 \mathrm{~nm}$ using a polarimeter (P-1010; JASCO Inc., Tokyo, Japan) at room temperature. The polysaccharide solution $(0.2 \%)$ was prepared in distilled water.

\section{7. ${ }^{1} \mathrm{H}$ - and ${ }^{13} \mathrm{C}$-Nulear Magnetic Resonance (NMR) Spectroscopy}

${ }^{1} \mathrm{H}$ - and ${ }^{13} \mathrm{C}-\mathrm{NMR}$ spectra were recorded on a $\alpha 500$ FT-NMR spectrometer (JEOL Ltd, Japan) at 500.00 and $125.65 \mathrm{MHz}$, respectively. The polysaccharide (2\%, W/V) was dissolved in $\mathrm{D}_{2} \mathrm{O}$ and recorded at $37^{\circ} \mathrm{C}$ or $60^{\circ} \mathrm{C}$. The ${ }^{1} \mathrm{H}$ - and ${ }^{13} \mathrm{C}$-NMR chemical shifts were expressed in parts per million (ppm) relative to sodium 3-(trimethylsilyl) propionic-2,2,3,3-d, acid (TSP, $0.00 \mathrm{ppm}$ ), which was used as an internal standard.

\subsection{Methylation Analysis}

The polysaccharide (5 mg) was methylated according to the procedure described by Ciucanu and Kerek [47]. The obtained permethylated polysaccharide was subjected to complete acid hydrolysis using $2 \mathrm{M}$ TFA $(2 \mathrm{~mL})$ at $120^{\circ} \mathrm{C}$ for $2 \mathrm{~h}$. The hydrolysate was dissolved in $1 \mathrm{M} \mathrm{NH}_{4} \mathrm{OH}(0.2 \mathrm{~mL})$. DMSO $(1 \mathrm{~mL})$ containing $20 \mathrm{mg}$ of $\mathrm{NaBH}_{4}$ was added and the mixture was incubated at $40^{\circ} \mathrm{C}$ for $90 \mathrm{~min}$. Subsequently acetic anhydride $(0.2 \mathrm{~mL})$ was added to the mixture. Anhydrous 1-methylimidazole $(0.2 \mathrm{~mL})$ and acetic anhydride $(1 \mathrm{~mL})$ were then added, and the reaction mixture was incubated at ambient temperature for $10 \mathrm{~min}$. After extraction with chloroform and washing with water, partially methylated alditol acetates were obtained.

The partially methylated alditol acetates were analyzed using a gas chromatograph (GC-14A; Shimadzu Corp., Kyoto, Japan) equipped with a flame ionization detector using a capillary column (DB-1: $40 \mathrm{~m} \times 0.25 \mathrm{~mm}$, J\&W Scientific Inc., CA, U.S.A.). The injector and detector temperatures were $210^{\circ} \mathrm{C}$ and $270^{\circ} \mathrm{C}$, respectively. After injection, the oven temperature was maintained at $150^{\circ} \mathrm{C}$ for $5 \mathrm{~min}$, and then raised at $5^{\circ} \mathrm{C} / \mathrm{min}$ to $250^{\circ} \mathrm{C}$. This temperature was maintained for $5 \mathrm{~min}$. The identities of the peaks were confirmed using GC-MS (GCMS-QP 1000EX; Shimadzu Corp., Kyoto, Japan) under the same conditions.

\section{Results}

\subsection{Preparation of Polysaccharide}

Ulva pertusa reached 12 - $20 \mathrm{~cm}$ long having two cell layers thick and round blade. The collected seaweed was washed with tap water and then dried in air-dried oven at $40^{\circ} \mathrm{C}$ for $24 \mathrm{~h}$. A polysaccharide was prepared and purified as described in Materials and methods.

\subsection{Chemical Components of the Polysaccharide}

The yield of purified polysaccharide was estimated to be $21.7 \%$ of the algal dry weight after the first ethanol precipitation. The polysaccharide yield was reduced to $8.5 \%$ after purification based on the dried weight of algae. The polysaccharide was $67.3 \%$ (W/W) carbohydrates. The purified polysaccharide also contained $23.8 \%$, $19.7 \%$ and $22.6 \%$ of uronic acid, sulfate and ash, respectively. The results are summarized in Table 1. 
An anion exchange high-performance liquid chromatogram of the hydrolysate of the polysaccharide (Figure 1) showed that peaks 1,2 and 3 were L-rhamnose, D-glucose and D-xylose in the molar ratio of 4.0:0.1:0.3. The result indicates that the polysaccharide isolated from Ulva pertusa is an ulvan [43]. D-Dlucuronic acid and L-idulonic acid was identified by anion exchange high-performance liquid chromatography in the molar ratio of 1.0:0.2, as shown in Figure 2.

\subsection{Specific Rotation and Infrared Spectrum (IR) of the Polysaccharide}

The specific rotation $[\alpha]_{589}$ of the ulvan $\left(0.2 \%\right.$ in water) at $25^{\circ} \mathrm{C}$ showed a value of $-0.006^{\circ}$, indicating that $\alpha$ and $\beta$ linkages were both involved.

In the IR spectrum of the ulvan presented in Figure 3, the major absorption at approximately $3400 \mathrm{~cm}^{-1}$ was attributed to the stretching of hydroxyl groups. Absorption at $2900 \mathrm{~cm}^{-1}$ resulted from C-H stretching of C-H groups. Absorption at $1638 \mathrm{~cm}^{-1}$ resulted from $\mathrm{C}=\mathrm{O}$ of uronic acid. The absorption at $1250 \mathrm{~cm}^{-1}$ and two shoulder absorptions at 850 and $780 \mathrm{~cm}^{-1}$ were indicative of the presence of sulfate ester substitutions. The absorption at the former, $1250 \mathrm{~cm}^{-1}$, was attributed to C-O-S stretching. The band at $1053 \mathrm{~cm}^{-1}$ corresponds to the stretching of the $\mathrm{C}=\mathrm{O}$ of uronic acid and the vibration of the $\mathrm{C}-\mathrm{O}-\mathrm{C}$ bridge of the glucosides [43].

Table 1. Chemical components of the polysaccharide.

\begin{tabular}{cccc}
\hline Carbohydrates $(\%, \mathrm{~W} / \mathrm{W})$ & Uronic acid (\%) & $\mathbf{S O}_{\mathbf{4}}(\mathbf{\%})$ & Ash (\%) \\
\hline 67.3 & 23.8 & 19.7 & 22.6 \\
\hline
\end{tabular}

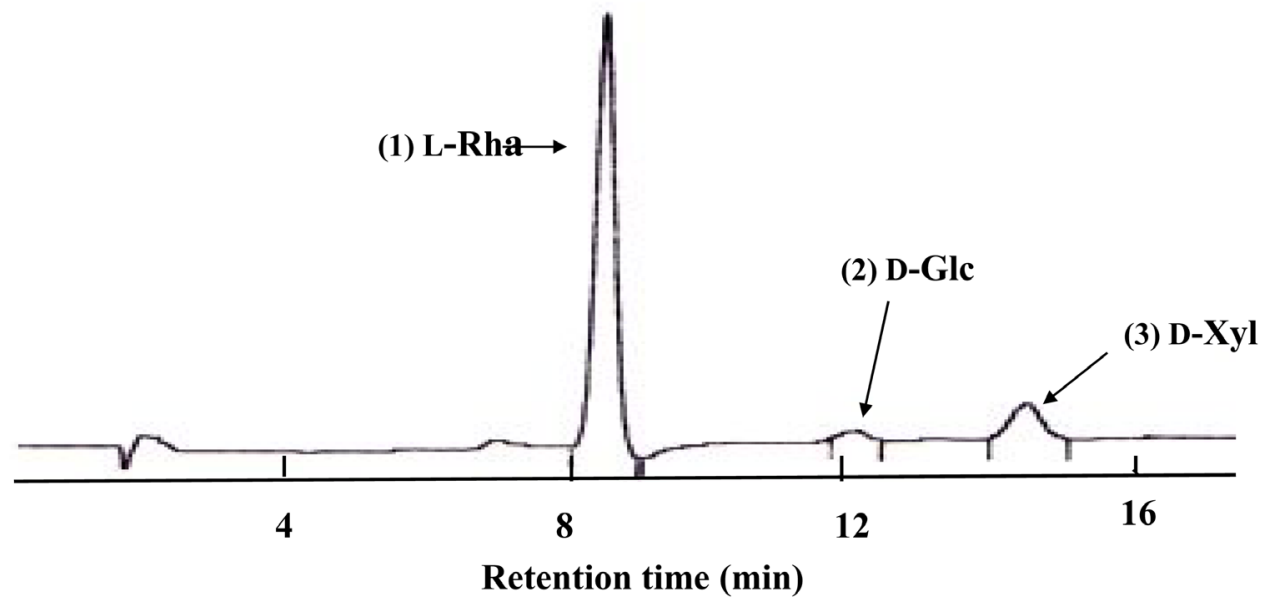

Figure 1. Liquid chromatogram of hydrolysate of the ulvan.

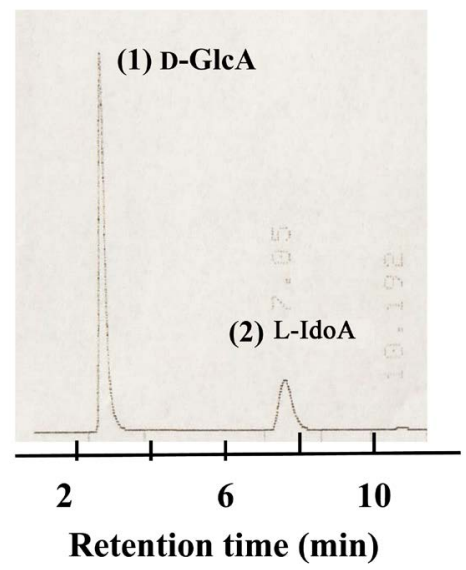

Figure 2. Liquid chromatogram of hydrolysate of the ulvan. 


\section{4. ${ }^{13} \mathrm{C}$ - and ${ }^{1} \mathrm{H}-\mathrm{NMR}$ Spectra of the Ulvan}

The ${ }^{13} \mathrm{C}$-NMR spectra of native and desulfated ulvan are presented in Figure $4(\mathrm{a})$, measured at $37^{\circ} \mathrm{C}$, and $4 \mathrm{~b}$, measured at $60^{\circ} \mathrm{C}$. The four sugar moieties were designated as residues $\mathrm{A}, \mathrm{B}, \mathrm{C}$, and $\mathrm{D}$ according to their decreasing anomeric carbon chemical shifts, as shown in Figure 4(a). The ${ }^{13} \mathrm{C}$-NMR spectra were well characterized in papers published by Lahaye et al. [48]-[52]. The signals A (106.14 ppm), B (105.91), C (103.88) and D (102.82) were assigned to $\beta$-D-glucuronic acid, $\alpha$-L-idulonic acid, 1,4-linked $\alpha$-L-rhamnose substituted with sugar and 1,4-linked $\alpha$-L-rhamnose, respectively [50]-[52]. The many ring-carbon signals (70 - 85 ppm) were also assigned as indicated in Figure 4(a) and are presented in Table 2. Six anomeric signals were observed in desulfated ulvan (Figure 4(b)). The new signal E (106.75 ppm) was assigned to $\beta$-D-xylose [50], but signal F (101.75 ppm) was unidentified. Methyl signals at 19.82 and $19.58 \mathrm{ppm}$ were observed, indicating that L-rhamnosyl residues were involved in the ulvan [50] [51]. Two carboxyl carbons (A6 and B6) at 175.58 and 175.43 ppm were assigned to D-glucuronic acid and L-idulonic acid residue, respectively [50]-[52]. The many ring-carbon signals (70 - 85 ppm) were also assigned as indicated in Figure 4(b) and are presented in Table 2.

The ${ }^{1} \mathrm{H}$ spectra of the native and desulfated ulvan are presented in Figure $5(\mathrm{a})\left(37^{\circ} \mathrm{C}\right)$ and Figure $5(\mathrm{~b})\left(60^{\circ} \mathrm{C}\right)$. For the native sample, six chemical signals were observed in the anomeric region $(\delta 5.5$ - 4.5) at 5.264, 5.058, 4.871, 4.760, 4.603 and 4.573 ppm. From the published papers [50] [51], signals A (4.603 ppm), B (5.264 ppm), $\mathrm{C}(4.871 \mathrm{ppm}), \mathrm{D}(4.760 \mathrm{ppm}), \mathrm{E}(4.573 \mathrm{ppm})$ and $\mathrm{F}(5.058 \mathrm{ppm})$ were assigned to be $\beta$-D-glucuronic acid, $\alpha$-L-idulonic acid,1,4-linked $\alpha$-L-rhamnose substituted with side-chain, 1,4-linked $\alpha$-L-rhamnose, $\beta$-D-xylose, and an unknown sugar, respectively. From a published paper [38], signal F (5.058 ppm) was assigned to be 1,3-linked $\alpha$-L-rhamnose. Large signals at 1.340 and $1.329 \mathrm{ppm}$ were observed, indicating that an L-rhamnosyl residue was involved. Six anomeric signals, A (4.735 ppm: D-glucuronic acid), B (5.281 ppm: L-idulonic acid), C (4.861 ppm: $\alpha$-1,4-linked L-rhamnose substituted with sugar), D (4.764 ppm: $\alpha$-1,4-linked L-rhamnose), E (4.547 ppm: D-xylose) and F (5.186 ppm) were also observed in desulfated ulvan (Figure 5(b)). From a published paper [38], signal F (5.18 ppm) was assigned to be $\alpha$-1,3-linked $\alpha$-L-rhamnose. The results are presented in Table 3.

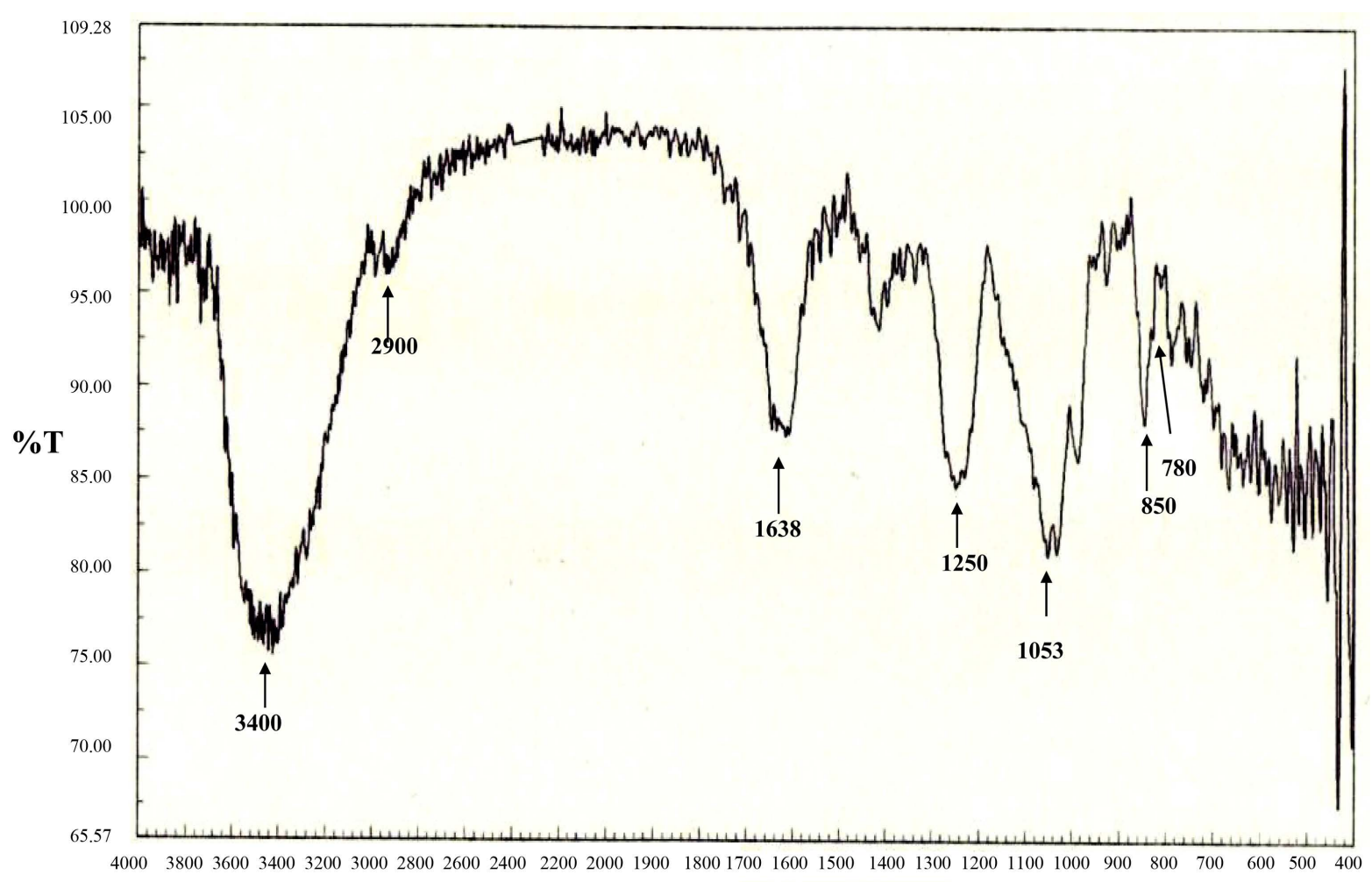

Wave number $\left(\mathrm{cm}^{-1}\right)$

Figure 3. Infrared spectrum of the ulvan at $4000-400 \mathrm{~cm}^{-1}$. 


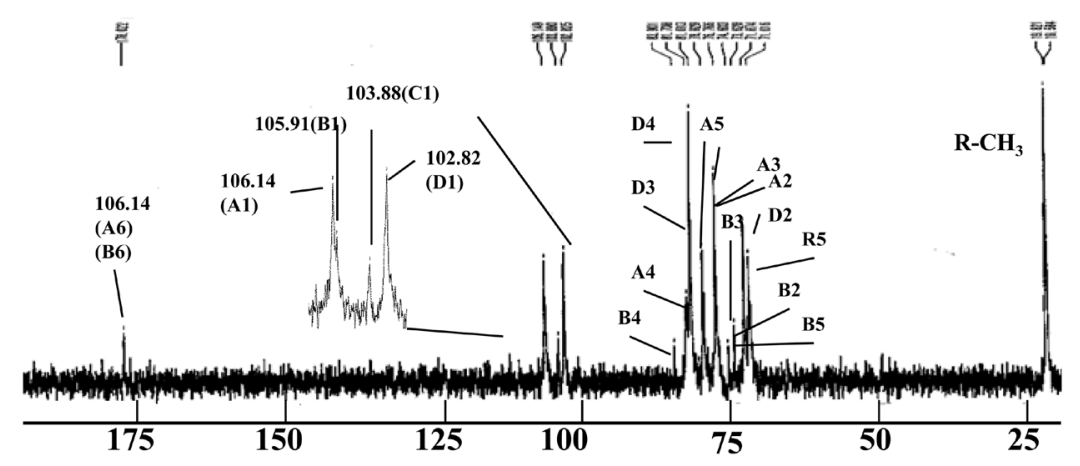

(a)

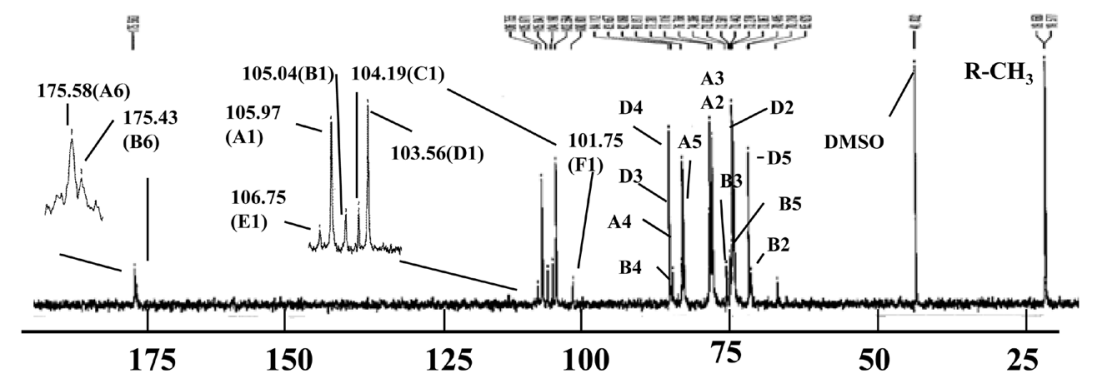

(b)

Chemical shift (ppm)

Figure 4. ${ }^{13} \mathrm{C}$-NMR spectra of the ulvan in $\mathrm{D}_{2} \mathrm{O}$ at $37^{\circ} \mathrm{C}$ for (a) and $60^{\circ} \mathrm{C}$ for (b). (a) Native and (b) desulfated ulvan.

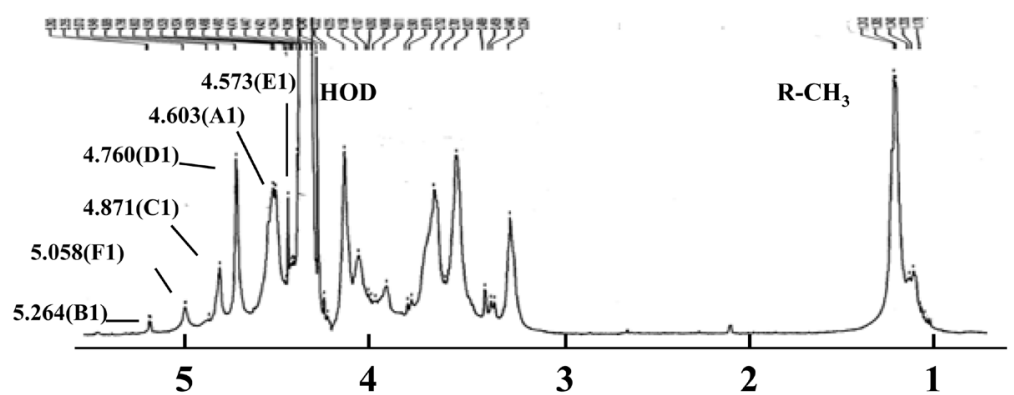

(a)

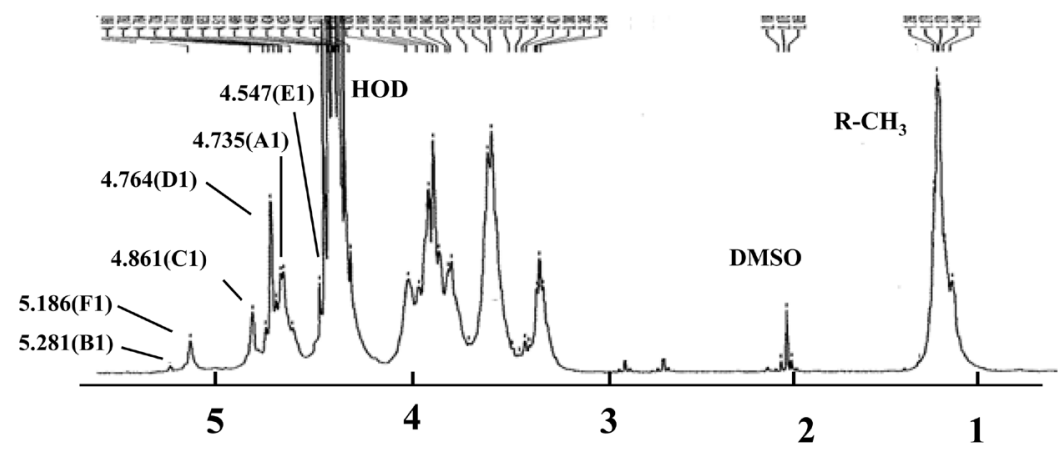

(b)

\section{Chemical shift (ppm)}

Figure 5. ${ }^{1} \mathrm{H}-\mathrm{NMR}$ spectra of the ulvan in $\mathrm{D}_{2} \mathrm{O}$ at $37^{\circ} \mathrm{C}$ for (a) and $60^{\circ} \mathrm{C}$ for (b). (a) Native ulvan and (b) desulfated ulvan. 
Table 2. Chemical shifts of resonances in the ${ }^{13} \mathrm{C}$ NMR spectra of native and desulfated ulvan.

\begin{tabular}{|c|c|c|c|c|c|c|}
\hline \multirow{2}{*}{ Residue } & \multicolumn{6}{|c|}{ Chemical shifts $(\delta, \mathrm{ppm})$} \\
\hline & ${ }^{\mathrm{a}} \mathrm{C} 1 /{ }^{\mathrm{b}} \mathrm{C} 1$ & ${ }^{\mathrm{a}} \mathrm{C} 2 /{ }^{\mathrm{b}} \mathrm{C} 2$ & ${ }^{\mathrm{a}} \mathrm{C} 3 /{ }^{\mathrm{b}} \mathrm{C} 3$ & ${ }^{\mathrm{a}} \mathrm{C} 4 /{ }^{\mathrm{b}} \mathrm{C} 4$ & ${ }^{\mathrm{a}} \mathrm{C} 5 /{ }^{\mathrm{b}} \mathrm{C} 5$ & ${ }^{\mathrm{a}} \mathrm{C} 6 /{ }^{\mathrm{b}} \mathrm{C} 6$ \\
\hline$\underset{\beta \text {-D-GlcA }(1 \rightarrow}{\mathrm{A}}$ & $106.14 / 105.97$ & 76.760/77.11 & $76.76 / 77.28$ & $83.90 / 83.65$ & 78.92/81.81 & $178.02 / 175.58$ \\
\hline$\underset{\alpha \text {-L-IdoA }(1 \rightarrow}{\mathrm{B}}$ & $105.91 / 105.04$ & 73.62/73.83 & $74.60 / 74.38$ & $83.94 / 83.65$ & 73.62/73.44 & $178.02 / 175.43$ \\
\hline $\begin{array}{c}\mathrm{C}^{*} \\
\rightarrow 4)-\alpha-\mathrm{L}-\text { Rha- }(1 \rightarrow\end{array}$ & 103.88/104.19 & & & & & $19.58 / 19.57$ \\
\hline$\underset{\mathrm{D}}{\mathrm{D}}$ & $102.82 / 103.56$ & 73.87/73.06 & $81.01 / 84.11$ & $81.01 / 84.11$ & 71.01/70.49 & $19.82 / 19.58$ \\
\hline$\underset{\rightarrow 4)-\beta \text {-D-Xyl-(1 } \rightarrow}{\mathrm{E}}$ & $/ 106.75$ & & & & & \\
\hline$\underset{\rightarrow 3)-\alpha \text {-L-Rha-(1 } \rightarrow}{\text { F }}$ & $/ 101.75$ & & & & & \\
\hline
\end{tabular}

${ }^{\mathrm{a}}$ Native and ${ }^{\mathrm{b}}$ desulfated ulvan. ${ }^{*}$ Branching L-rhamnose.

Table 3. Chemical shifts of resonances in the anomeric proton NMR spectra of native and desulfated ulvan.

\begin{tabular}{|c|c|}
\hline \multicolumn{2}{|c|}{ Chemical shifts ( $\delta$, ppm) } \\
\hline Residue & ${ }^{\mathrm{a}} \mathrm{H} 1 /{ }^{\mathrm{b}} \mathrm{H} 1$ \\
\hline$\underset{\beta \text {-D-GlcA }(1 \rightarrow}{\mathrm{A}}$ & $4.603 / 4.735$ \\
\hline$\underset{\alpha-\mathrm{B}-\mathrm{IdoA}(1 \rightarrow}{\mathrm{B}}$ & $5.264 / 5.281$ \\
\hline $\begin{array}{c}C^{*} \\
\rightarrow 4)-\alpha-L-R h a-(1 \rightarrow\end{array}$ & $4.871 / 4.861$ \\
\hline$\underset{\text { D }}{\rightarrow 4)-\alpha-\text {-Lha- }(1 \rightarrow}$ & $4.760 / 4.764$ \\
\hline 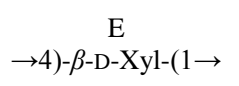 & $4.573 / 4.547$ \\
\hline$\underset{\rightarrow 3)-\alpha-L-R h a-(1 \rightarrow}{\text { F }}$ & $5.058 / 5.186$ \\
\hline
\end{tabular}

${ }^{\mathrm{a}}$ Native and ${ }^{\mathrm{b}}$ desulfated ulvan. ${ }^{*}$ Branching L-rhamnose.

\subsection{Methylation Analysis}

The native and desulfated ulvan was methylated according to the procedure described by Ciucanu \& Kerek [47]. The obtained permethylated ulvan was subjected to complete acid hydrolysis to furnish mixtures of the methylated sugars which were analyzed as the corresponding alditol acetates using gas-liquid chromatography (GC) and combined gas-liquid chromatography/mass spectroscopy (MS). The chromatograms are shown in Figure 6(a) (native ulvan) and Figure 6(b) (desulfated ulvan). Partially methylated alditol acetates were identified using published data [53] [54]. For the native ulvan (Figure 6(a)), the following 9 peaks were observed: terminal 2,3,4-tri-O-methyl-D-glucuronic acid (1), terminal 2,3,4-tri- $O$-methyl-L-idulonic acid (2), 2,4-di- $O$-methyl-Lrhamnose (3), 2,3-di-O-methyl-L-rhamnose (4), 2-mono-O-methyl-L-rhamnose (5), 2,3-di-O-methyl D-xylose (6), 3-mono-O-methyl-L-rhamnose (7), 2-mono- $O$-methyl-D-xylose (8) and L-rhamnose (9).

After desulfation (Figure 6(b)), peaks 4 and 6 increased, while peaks 8 and 9 disappeared. The results indicated that sulfate groups were attached at C-2 and C-3 of L-rhamnose as well as C-3 of the D-xylose residue. The results are summarized in Table 4.

The data show that the native ulvan consists of terminal D-glucuronic acid, terminal L-idulonic acid, 1,4linked L-rhamnose, 1,3-linked L-rhamnose, 1,3,4-linked L-rhamnose, 1,2,4-linked L-rhamnose, 1,3,4-linked D-xylose and 1,2,3,4-linked L-rhamnose residues. 


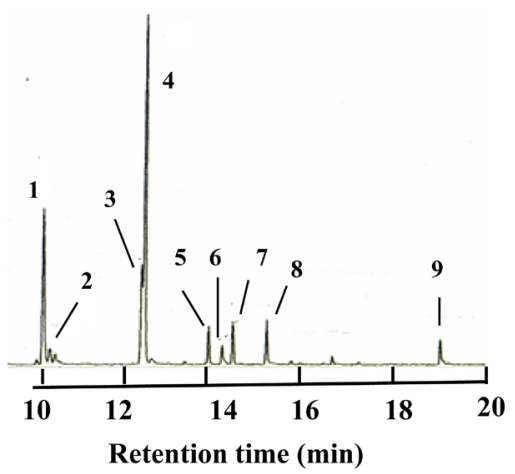

(a)

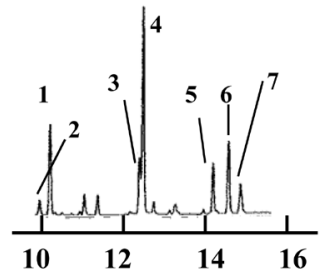

(b)

Figure 6. Gas chromatograms of partially methylated alditol acetate of the ulvan. (a) Native ulvan, (b) Desulfated ulvan.

Table 4. Methylation analysis of ulvan.

\begin{tabular}{|c|c|c|c|c|}
\hline \multirow{2}{*}{${ }^{\mathrm{a}}$ Number } & \multirow{2}{*}{ Methylated sugar } & \multicolumn{2}{|c|}{ Molar ratio } & \multirow{2}{*}{ Mode of linkage } \\
\hline & & Native & Desulfated & \\
\hline$(1)$ & 2,3,4-tri- $O$-methyl- $\beta$-D-glcuronic acid & 1.6 & 1.7 & $\beta$-D-glucuronic acid- $(1 \rightarrow$ \\
\hline$(2)$ & 2,3,4-tri-O-methyl- $\beta$-L-iduronic acid & 0.1 & $\operatorname{tr}$ & $\alpha$-L-idulonic acid- $(1 \rightarrow$ \\
\hline (3) & 2,4-di-O-methyl- $\alpha$-L-rhamnose & 1.0 & 1.0 & $\rightarrow 3)$ - $\alpha$-L-rhamnose-( $(1 \rightarrow$ \\
\hline (4) & 2,3-di-O-methyl- $\alpha$-L-rhamnose & 3.0 & 4.0 & $\rightarrow 4)$ - $\alpha$-L-rhamnose-( $1 \rightarrow$ \\
\hline (5) & 2-mono-O-methyl- $\alpha$-L-rhamnose & 0.3 & 0.8 & $\rightarrow 3,4-\alpha$-L-rhamnose- $(1 \rightarrow$ \\
\hline$(6)$ & 2,3-di-O-methyl- $\beta$-D-xylose & 0.1 & 0.4 & $\rightarrow 4)-\beta$-D-xylose $-(1 \rightarrow$ \\
\hline (7) & 3-mono-O-methyl- $\alpha$-L-rhamnose & 0.7 & 0.4 & $\rightarrow 2,4)-\alpha$-L-rhamnose-( $1 \rightarrow$ \\
\hline (8) & 2-mono- $O$-methyl- $\beta$-D-xylose & 0.4 & 0.0 & $\rightarrow 3,4)-\beta$-D-xylose- $(1 \rightarrow$ \\
\hline (9) & $\alpha$-L-rhamnose & 0.2 & 0.0 & $\rightarrow 2,3,4)-\alpha-$-L-rhamnose-( $1 \rightarrow$ \\
\hline
\end{tabular}

${ }^{\mathrm{a}}$ Peak number in Figure 6.

\section{Discussion}

Based on the NMR and methylation analysis of the ulvan as well as the chemical shifts reported in the literatures [48]-[52], residue A was assigned as terminal $\beta$-D-glucuronic acid, residue B as terminal $\alpha$-L-idulonic acid, residue $\mathrm{C}$ as 1,4 - linked $\alpha$-L-rhamnose substituted side-chain, residue $\mathrm{D}$ as 1,4 -linked $\alpha$-L-rhamnose, residue E as 1,4-linked $\beta$-D-xylose and residue $\mathrm{F}$ as 1,3-linked $\alpha$-L-rhamnose. After desulfation, peak 9 in Figure 5(a) disappeared in Figure 6(b), suggesting that sulfate groups were attached at C-2 and C-3 of the L-rhamnose residue on the main-chain. Furthermore, a sulfate group was attached at C-3 of the D-xylose residue because 2-mono$O$-methyl-D-xylose (peak 8 in Figure 6(a)) disappeared, but 2,3-di-methyl D-xylose (peak 6) increased after desulfation (Figure 6(b)). The residues of peaks 5 (2-mono-L-rhamnose) and 7 (3-mono-L-rhamnose) remained even after desulfation, suggesting that terminal sugars (D-glucuronic acid and L-idulonic acid) are substituted at C-2 and/or C-3 of the L-rhamnose residues.

Consequently, the chemical and structural results showed that the ulvan extracted from $U$. pertutsa consisted 


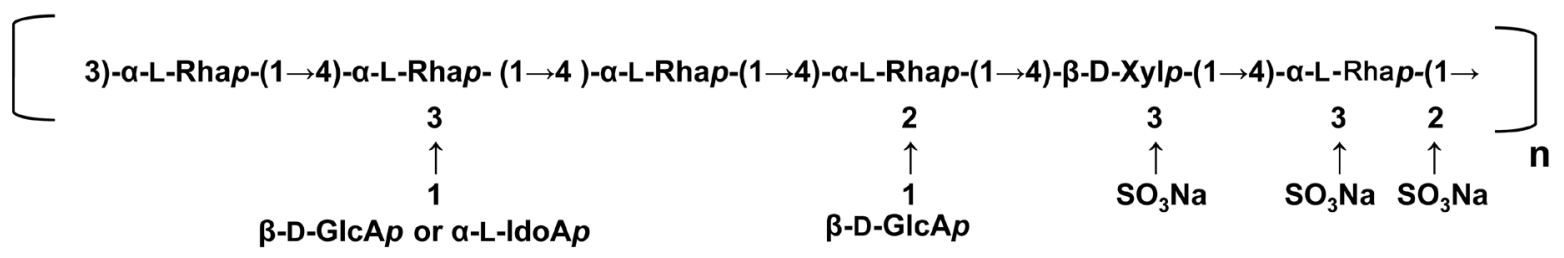

Figure 7. The structure of ulvan from Ulva fertusa.

of 1,4-linked $\alpha$-L-rhamnopyranose, 1,3-linked $\alpha$-L-rhamnopyranose, 1 ,4-linked $\beta$-D-xylopyranose, terminal $\beta$ D-glucuronic acid ( $>1.5$ molar) and terminal L-idulonic acid ( $<0.5$ molar). The terminal sugars were substituted at C-2 and/or C-3 of the 1,4-linked $\alpha$-L-rhamnose residue. The sulfate groups were attached at C-2 and C-3 of the L-rhamnopyranose as well as C-3 of the D-xylopyranose residues. In addition, some oligosaccharides, including $\alpha$-L-rhamnpyranose 3S-( $1 \rightarrow 4)-\beta$-D-xylopyranose $2 \mathrm{~S}, \beta$-D-glucuronic acid-( $1 \rightarrow 2)-\alpha$-L-rhamnopyranose$(1 \rightarrow 4)-\beta$-D-xylopyranose, $\alpha$-L-rhamnopyranose $3 \mathrm{~S}$-( $1 \rightarrow 4)-\beta$-D-xylopyranose $2 \mathrm{~S}$ - $(1 \rightarrow 4)-\alpha$-L-rhamnopyranose $3 \mathrm{~S}$ from ulvans were reported [42] [50].

\section{Conclusion}

Thus, on the basis of the results and discussion, we proposed the chemical structure of the ulvan (octa-saccharide repeating units) isolated from Ulva pertusa, as shown in Figure 7.

\section{References}

[1] Tako, M. and Nakamura, S. (1986) Indicative Evidence for a Conformational Transition in $\kappa$-Carrageenan from Studies of Viscosity-Shear Rate Dependence. Carbohydrate Research, 155, 200-205. http://dx.doi.org/10.1016/S0008-6215(00)90146-0

[2] Tako, M. and Nakamura, S. (1986) Synergistic Interaction between $\kappa$-Carrageenan and Locust Bean Gum in Aqueous Media. Agricultural and Biological Chemistry, 50, 2817-2822. http://dx.doi.org/10.1271/bbb1961.50.2817

[3] Tako, M. Nakamura, S. and Kohda, Y. (1987) Indicative Evidence for a Conformational Transition in $t$-Carrageenan. Carbohydrate Research, 161, 247-253. http://dx.doi.org/10.1016/S0008-6215(00)90081-8

[4] Tako, M. and Nakamura, S. (1988) Gelation Mechanism of Agarose. Carbohydrate Research, 180, 277-284. http://dx.doi.org/10.1016/0008-6215(88)80084-3

[5] Tako, M., Sakae, A. and Nakamura, S. (1989) Rheological Properties of Gellan Gum in Aqueous Media. Agricultural and Biological Chemistry, 53, 771-776. http://dx.doi.org/10.1271/bbb1961.53.771

[6] Tako, M., Teruya, T., Tamaki, Y. and Konishi, T. (2009) Molecular Origin for Rheological Characteristics of Native Gellan Gum. Colloid and Polymer Science, 287, 1445-1454. http://dx.doi.org/10.1007/s00396-009-2112-2

[7] Tako, M. (1993) Molecular Origin for Thermal Stability of Rhamsan Gum in Aqueous Media. Bioscience, Biotechnology and Biochemistry, 57, 1182-1184. http://dx.doi.org/10.1271/bbb.57.1182

[8] Tako, M., Tohma, S., Taira, T. and Ishihara, M. (2003) Gelation Mechanism of Deacetylated Rhamsan Gum. Carbohydrate Polymers, 54, 279-285. http://dx.doi.org/10.1016/S0144-8617(03)00029-8

[9] Tako, M. and Hizukuri, S. (1995) Evidence for Conformational Transition in Amylose. Journal of Carbohydrate Chemistry, 14, 613-622. http://dx.doi.org/10.1080/07328309508005362

[10] Tamaki, Y., Konishi, T. and Tako, M. (2011) Gelation and Retrogradation Mechanism of Wheat Amylose. Materials, 4, 1763-1775. http://dx.doi.org/10.3390/ma4101763

[11] Tako, M. and Hizukuri, S. (1997) Molecular Origin for the Thermal Stability of Rice Amylopectin. Journal of Carbohydrate Chemistry, 16, 655-666. http://dx.doi.org/10.1080/07328309708007343

[12] Tako, M. (1999) Molecular Origin for Thermal Stability of Waxy Rice Starch. Staerke/Starch,48, 414-417

[13] Tako, M. and Hizukuri, S. (2000) Molecular Origin for Thermal Stability of Koshihikari Rice Amylopectin. Food Research International, 33, 35-40. http://dx.doi.org/10.1016/S0963-9969(00)00021-1

[14] Tako, M. and Hizukuri, S. (2003) Rheological Properties of Wheat (Halberd) Amylopectin. Staerke/Starch, 55, 345-349. http://dx.doi.org/10.1002/star.200300138

[15] Tako, M., Hanashiro, I. and Uechi, S. (2004) Rheological Properties of Wheat Amylopectin. Science of Bulletin of Faculty of Agriculture, University of the Ryukyus, No. 51, 139-143. 
[16] Tako, M. and Hizukuri, S. (1999) Gelatinization Mechanism of Rice Starch. Journal Carbohydrate Chemistry, 18, 573584. http://dx.doi.org/10.1080/07328309908544020

[17] Tako, M. (2000) Gelatinization Characteristics of Rice Starch. Journal of Applied Glycoscience, 47, 187-192. http://dx.doi.org/10.5458/jag.47.187

[18] Tako, M. and Hizukuri, S. (2003) Gelatinization Mechanism of Potato Starch. Carbohydrate Polymers, 48, $397-401$. http://dx.doi.org/10.1016/S0144-8617(01)00287-9

[19] Tako, M., Tamaki, Y., Konishi, T., Shibanuma, K., Hanashiro, I. and Takeda, Y. (2008) Gelatinization and Retrogradation Characteristics of Wheat (Rosella) Starch. Food Research International, 41, 797-802. http://dx.doi.org/10.1016/j.foodres.2008.07.002

[20] Tako, M., Tamaki, Y., Teruya, T., Konishi, T., Shibanuma, K., Hanashiro, I. and Takeda, Y. (2009) Gelatinization Characteristics of Halberd Wheat Starch. Staerke/Starch, 61, 275-281. http://dx.doi.org/10.1002/star.200800073

[21] Tako, M. (2000) Structural Principles of Polysaccharide Gels. Journal of Applied Glycoscience, 47, 49-53. http://dx.doi.org/10.5458/jag.47.49

[22] Tako, M., Tamaki, Y., Teruya, T. and Takeda, Y. (2014) The Principles of Starch Gelatinization and Retrogradation. Food and Nutrition Sciences, 5, 280-291. http://dx.doi.org/10.4236/fns.2014.53035

[23] Tako, M. (2015) The Principle of Polysaccharide Gels. Advances in Bioscience and Biotechnology, 6, 22-36. http://dx.doi.org/10.4236/abb.2015.61004

[24] Tako, M. (1994) Identification of Agar from Gracilaria blodgettii and Its Gelling Characteristics. Ohyo Tohshitsu, Kagaku, 41, 305-311.

[25] Tako, M., Higa, M., Medoruma, K. and Nakasone, Y. (1999) A Highly Methylated Agar from Red Seaweed. Gracilaria arcuata, Botanica Marina, 42, 513-517. http://dx.doi.org/10.1515/BOT.1999.058

[26] Qi, X.Q., Tako, M. and Toyama, S. (1997) Chemical Characterization of $\kappa$-Carrageenan from Hypnea charoides. Journal of Applied Glycoscience, 44, 137-142.

[27] Lin, L.H., Tako, M. and Hongo, F. (2000) Isolation and Characterization of 1-Carrageenan from Eucheuma serra, Journal of Applied Glycoscience, 47, 303-310. http://dx.doi.org/10.5458/jag.47.303

[28] Tako, M., Uehara, M., Kawashima, Y., Chinen, I. and Hongo, F. (1996) Isolation and Identification of Fucoidan from Cladosiphon okamuranus. Journal of Applied Glycoscience, 43, 143-148.

[29] Tako, M., Nakada, T. and Hongo, F. (1999) Chemical Characterization of a Fucoidan from Commercially Cultured Nemacystus decipiens (Itomozuku). Bioscience, Biotechnology and Biochemistry, 53, 1813-1815. http://dx.doi.org/10.1271/bbb.63.1813

[30] Shiroma, R., Uechi, S., Taira, T., Ishihara, M., Tawata, S. and Tako, M. (2003). Isolation and Characterization of Fucoidan from Hijikia fusiformis. Journal of Applied Glycoscience, 50, 361-365. http://dx.doi.org/10.5458/jag.50.361

[31] Tako, M., Kiyuna, S. and Hongo, F. (2001) Isolation and Characterization of Alginate from Commercially Cultured Nemacystus decipiens. Bioscience, Biotechnology and Biochemistry, 63, 654-657. http://dx.doi.org/10.1271/bbb.65.654

[32] Tako, M., Yoza, E. and Tohma S. (2000) Chemical Characterization of Acetyl Fucoidan and Alginate from Commercially Cultured Cladosiphon okamuranus. Botanica Marina, 43, 393-398. http://dx.doi.org/10.1515/BOT.2000.040

[33] Pakdee, P., Kinjyo, K., Tako, M., Tamaki, Y., Tomita, Y. and Yaga, S. (1995) Water-Soluble Polysaccharide from Seeds of Trees I. Galactomannan from Seeds of Leucaena leucocephala de WIT. Mokuzai Gakkaishi, 41, 440-443.

[34] Tamaki, Y., Teruya, T. and Tako, M. (2010) Chemical Structure of Galactomannan from Delonix regia. Bioscience, Biotechnology, and Biochemistry, 74, 1110-1112. http://dx.doi.org/10.1271/bbb.90935

[35] Tamaki, Y., Uechi, S., Taira, T., Ishihara, M., Adaniya, S., Uesato, K., Fukuta, M. and Tako, M. (2008) Isolation and Characterization of Pectin from Pericarp of Citrus depressa. Journal of Applied Glycoscience, 51, 19-25. http://dx.doi.org/10.5458/jag.51.19

[36] Tamaki, Y., Konishi, T., Fukuta, M. and Tako, M. (2008) Isolation and Structural Characterization of Pectin from Endocarp of Citrus depressa. Food Chemistry, 107, 352-364. http://dx.doi.org/10.1016/j.foodchem.2007.08.027

[37] Tamaki, Y. and Tako, M. (2008) Isolation and Characterization of Pectin from Peel of Citrus tankan. Bioscience, Biotechnology and Biochemistry, 72, 896-899. http://dx.doi.org/10.1271/bbb.70706

[38] Nakamura, M., Yamashiro, Y., Konishi, T., Hanashiro, I. and Tako, M. (2011). Structural Characteristics of Rhamnan Sulfate from Commercially Cultured Monostroma nitidum. Nippon Shokuhin Kagaku Kogaku Kaishi, 58, $245-251$.

[39] Tako M. (2002) The Acetyl Fucoidan and Its Manufacturing Methods from Commercially Cultured Cladosiphon okamuranus. Japanese Patent No. 3371124.

[40] Teruya T., Konishi T., Uechi S., Tamaki, H. and Tako, M. (2007) Anti-Proliferative Activity of Over Sulfated Fucoi- 
dan from Commercially Cultured Cladisiphon okamuranus TOKIDA in U937 Cells. International Journal of Biological Macromolecules, 41, 221-226. http://dx.doi.org/10.1016/j.ijbiomac.2007.02.010

[41] Teruya, T., Tatemoto, H., Konishi, T. and Tako, M. (2009) Structural Characteristics and in Vitro Macrophage Activation of Acetyl Fucoidan from Cladosiphon okamuranus. Glycoconjugate Journal, 26, 1019-1018. http://dx.doi.org/10.1007/s10719-008-9221-x

[42] Lahaye, M. and Robic, A. (2003) Structural and Functional Properties of Ulvan, a Polysaccharide from Green Seaweeds. Biomacromolecules, 8, 1765-1774. http://dx.doi.org/10.1021/bm061185q

[43] Yu, P.Z., Zhang, Q.B., Li, N., Xu, Z.H., Wang, Y.M. and Li, Z.E. (2003) Polysaccharides from Ulva pertusa (Chlorophyta) and Preliminary Studies on Their Antihyperlipidemia Activity. Journal of Applied Phycology, 15, 21-27. http://dx.doi.org/10.1023/A:1022997622334

[44] Tabarsa, M., Jee, S.J. and You, S.G. (2012) Structural Analysis of Immunostimulating Sulfated Polysaccharides from Ulva pertusa. Carbohydrate Research, 361, 143-147. http://dx.doi.org/10.1016/j.carres.2012.09.006

[45] Dubois, M., Gilles, K.A., Hamilton, J.K., Rebers, P.A. and Smith, F. (1956) Colorimetric Method for Determination of Sugars and Related Substances. Analytical Chemistry, 28, 350-356. http://dx.doi.org/10.1021/ac60111a017

[46] Bitter, B. and Muir, H.M. (1962) A Modified Uronic Acid Carbazole Reaction. Analytical Biochemistry, 4, $330-334$. http://dx.doi.org/10.1016/0003-2697(62)90095-7

[47] Ciucanu, J. and Kerek, F. (1984) A Simple and Rapid Method for the Permethylation of Carbohydrates. Carbohydrate Research, 131, 209-217. http://dx.doi.org/10.1016/0008-6215(84)85242-8

[48] Lahaye, M. and Ray, B. (1996) Cell-Wall Polysaccharides from the Marine Green Alga Ulva "Rigida” (Ulvales, Chlorophyta)-NMR Analysis of Ulvan Oligosaccharides. Carbohydrate Research, 283, 161-173. http://dx.doi.org/10.1016/0008-6215(95)00407-6

[49] Lahaye, M., Brunel, M. and, Bonnin, E. (1997) Fine Chemical Structure Analysis of Oligosaccharides Produced by an Ulvan-Lyase Degradation of the Water-Soluble Cell-Wall Polysaccharides from Ulva sp (Ulvales, Chlorophyta). Carbohydrate Research, 304, 325-333. http://dx.doi.org/10.1016/S0008-6215(97)00270-X

[50] Lahaye, M. (1998) NMR Spectroscopic Characterization of Oligosaccharides from Two Ulva rigida Ulvan Samples (Ulvales, Chlorophyta) Degraded by a Myase. Carbohydrate Research, 314, 1-12. http://dx.doi.org/10.1016/S0008-6215(98)00293-6

[51] Lahaye, M., Inizan, F. and Vigouroux, J. (1998) NMR Analysis of the Chemical Structure of Ulvan and of UlvanBoron Complex Formation. Carbohydrate Polymers, 36, 239-249. http://dx.doi.org/10.1016/S0144-8617(98)00026-5

[52] Lahaye, M., Cimadevilla, E.A.C., Kuhlenkamp, R., Quemener, B., Lognone, V. and Dion, P. (1999) Chemical Composition and ${ }^{13} \mathrm{C}-\mathrm{NMR}$ Spectroscopic Characterization of Ulvans from Ulva (Ulvales, Chlorophyta). Journal of Applied Phycology, 11, 1-7. http://dx.doi.org/10.1023/A:1008063600071

[53] Jansson, P.E., Kenne, L., Liedgren, H. and Lindberg, B. (1976) A Practical Guide to the Methylation Analysis of Carbohydrates. Chemistry Communication, Stockholm University, 8, 1-74

[54] Sasaki, G.L., Gorin, P.A.J., Souza, L.M., Czelusniak, P.A. and Iakomini, M. (2003) Rapid Synthesis of Partially $O$-Methylated Alditol Acetate as Standards for GC-MS: Some Relative Activities of Hydroxyl Groups of Methyl Glucopyran. Carbohydrate Research, 340, 731-739. http://dx.doi.org/10.1016/j.carres.2005.01.020 